\title{
Socio-Technical Viability Framework for Micro Hydropower in Group Water-Energy Schemes
}

\author{
Kemi Adeyeye $^{1, *(1)}$, John Gallagher ${ }^{2}\left(\mathbb{D}\right.$, Aonghus McNabola ${ }^{2}\left(\mathbb{D}\right.$, Helena M. Ramos ${ }^{3}\left(\mathbb{D}\right.$ and Paul Coughlan ${ }^{4}$ \\ 1 Department of Architecture and Civil Engineering, University of Bath, Claverton Down, Bath BA2 7AY, UK \\ 2 Department of Civil, Structural \& Environmental Engineering, Trinity College Dublin, The University of \\ Dublin, College Green, D02 PN40 Dublin, Ireland; j.gallagher@tcd.ie (J.G.); amcnabol@tcd.ie (A.M.) \\ 3 Civil Engineering, Architecture and Georesources Department, CERIS, Instituto Superior Técnico, \\ Universidade de Lisboa, Av. Rovisco Pais, 1049-001 Lisboa, Portugal; hramos.ist@gmail.com \\ 4 Trinity Business School, Trinity College Dublin, The University of Dublin, College Green, \\ D02 PN40 Dublin, Ireland; coughlnp@tcd.ie \\ * Correspondence: k.adeyeye@bath.ac.uk
}

Citation: Adeyeye, K.; Gallagher, J.; McNabola, A.; Ramos, H.M.;

Coughlan, P. Socio-Technical Viability Framework for Micro Hydropower in Group Water-Energy Schemes. Energies 2021, 14, 4222. https:// doi.org/10.3390/en14144222

Academic Editors: Maarten Wolsink and Poul Alberg Østergaard

Received: 7 May 2021

Accepted: 7 July 2021

Published: 13 July 2021

Publisher's Note: MDPI stays neutral with regard to jurisdictional claims in published maps and institutional affiliations.

Copyright: () 2021 by the authors. Licensee MDPI, Basel, Switzerland. This article is an open access article distributed under the terms and conditions of the Creative Commons Attribution (CC BY) license (https:// creativecommons.org/licenses/by/ $4.0 /)$.

\begin{abstract}
Most renewable energy (RE) studies focus on technology readiness, environmental benefits and/or cost savings. The market permeation, viability and adoption of RE technologies such as micro hydropower (MHP), however, require the alignment of other interrelated factors, such as the socio-technical, institutional and political dimensions. This is particularly the case where the energy recovery potential in decentralised water networks is being explored as part of a wholesome sustainability strategy by and for individual and communal prosumers. This study employs a socio-technical approach to understand factors that influence the perceived viability and adoption of MHP in group water-energy schemes. Methods included a progressive literature review to formulate a conceptual framework for the implementation of MHP systems. The framework was validated using survey data from representative stakeholders from groups schemes in Ireland and Spain. These stakeholders were sampled and surveyed at the stage of considering the adoption of MHP in their water networks. The findings highlight the push-pull factors and discusses the opportunities and barriers to the adoption of MHP systems. It confirms that the market, institutional and policy context, cost and financial benefits, social support and collaborative services combine to influence the adoption of MHP technology. Thus, a framework for evaluating the socio-technical viability of MHP systems based on these more realistic integrated, multi-dimensional criteria is proposed.
\end{abstract}

Keywords: conceptual framework; group water-energy scheme; micro hydropower; socio-technical approach; prosumers; social adoption and viability

\section{Introduction}

The world's energy use is forecast to increase by approximately $50 \%$ in the next 30 years [1]. This demand on fossil fuels is unsustainable and cannot continue to dominate energy provision into the future without addressing the associated climate change impacts [2]. Aligned with the Paris Agreement and the falling costs of renewable technologies, the EU's 2030 vision includes strategies to increase the penetration of Renewable Energy (RE) technologies, setting a 45\% target for RE production and a $40 \%$ reduction of greenhouse gas emissions [3]. The widespread adoption of RE systems will support energy security as part of the transition from society's reliance on fossil fuels [4]. The provision of low-carbon RE is important within the broader concept of the water-energy-food nexus, which is underpinned by maximising the potential and circularity of resources [5,6]. In 2018, RE accounted for an estimated $18.9 \%$ of total final energy consumption (TFEC) in Europe; therefore, there is scope for extensive growth in this sector [7].

Hydropower is the second largest RE source in Europe, contributing towards one-third of electricity sourced from renewables [8]. Therefore, it remains an important contributor 
for reducing the environmental impacts of Europe's energy demands and complex energy nexus [9]. Small hydropower contributes to 3\% of the total electricity generation in Europe, with over 17,800 schemes providing a total installed capacity of $12,333 \mathrm{MW}$ in the EU-27 [10]. The common techniques, technologies and environmental and climate change impact of micro hydropower (MHP), i.e., less than 100 kilowatts $(\mathrm{kW})$ in size, have been extensively studied by [11-14]. Recent technical advances, including Pump-as-Turbines (PAT), enable MHP systems to be deployed such that geographical, technical, environmental and economic constraints are reduced [4]. This leaves a gap in addressing constraints in the interaction between technological push (advancements in product development) and societal pull (market/user demand) factors [15,16].

Societal factors, including cultural and institutional, can potentially override the technological dimensions, e.g., the environmental impacts of RE technology production and affect adoption [17]. The average consumption of electricity per capita differs globally by a magnitude of three [18]. Prompting Spreng [19] to propose a 2-kW society, where everyone is provided with $63 \mathrm{GJ} /$ capita/year to maintain a good quality of life, and to address energy inequalities.

Phasing out fossil fuels can be socially and economically painful for many countries [20]. Therefore, the adoption of MHP and other small scale RE systems can also support national transitions towards creating low carbon, decentralised renewable energy communities (RECs) [15,21-23]. Pragmatically, the EU also recognises the need to transition citizens from passive energy consumers to active energy citizens-the so-called RE prosumers [23]. Thus, EU energy policy is also transitioning to mainstream RE prosumers in each Member State [24], leading to the emergence of RE communities of interest, RE citizen groups or RE self-groups.

Regulations play a structural role in the energy transition but can be highly complex, given the growing variety of schemes, business models, typologies of prosumers and grid-related issues [25]. EU regulations are increasingly designed to promote the update of RE technologies, placing the consumer at the centre of policies and markets. Depending on the regulatory framework of each EU region, communities, to varying degrees, can benefit from conducive policy and incentives to promote self-production and/or consumption of renewable energy. For instance, the EU have proposed important changes to its Internal Electricity Market Directive (EU) 2019/944 (as amended), which: (a) provides consumers with more tools for active participation in the energy market, (b) introduces measures to improve retail market competition and (c) sets out principles to ensure that aggregators can fulfil their role as intermediaries between customers and the wholesale market. Amendments were also made to the Renewable Energy Directive (RED II) (EU) 2018/2001 (recast) on the promotion of the use of energy from renewable sources. From June 2021, RE prosumers will have the right to consume, store or sell RE generated on their premises [23]: (a) individually, that is, households and non-energy small and medium sized enterprises (SMEs), and collectively, for example in tenant electricity projects (Art. 21 RED II), or (b) as part of Renewable Energy Communities organised as independent legal entities (Art. 22 RED II).

The implementation and adoption of MHP systems now need to consider other factors beyond energy efficiency to reduce the per capita or process consumption [26,27]. With ongoing transitions in environmental and policy drivers, the final aspect is stakeholder or community buy-in and legitimacy [21,28], especially as new MHP technological innovation beyond the conventional run-of-river schemes-energy recovery by installing MHP in water distribution networks - are yet to be fully realised in Europe [29-31]. Even though they have the potential to increase the overall efficiency of water supply whilst contributing towards sectoral energy demands. Studies have addressed the technical, economic and environmental factors which govern the success of MHP applications in water networks which supply the public or for irrigation [32-34]. A total of $1.5 \mathrm{GW}$ of MHP potential has already been recovered in water pipe networks the UK, with 10-fold more energy being 
available through new installations [35]. An estimated $0.07 \mathrm{MWh} /$ year/ha of mean energy has been shown to be recoverable from pressurised irrigation networks in Spain [32].

The lack of stakeholder knowledge, complex planning requirements and management needs $[21,36]$ affect the adoption of MHP systems. Thus, the need to understand the socio-technical evidence, emergence of new actors and changes in behaviour and practice by stakeholders [37-39] by addressing the two aspects influencing the adoption of technological innovation: functionality (evaluating consumption, value and risk) and socio-psychological impact (e.g., conflict with awareness and perceptions) [40-42]. Without this, MHP will remain a largely untapped potential, including the 28,000 feasible sites across Europe [35].

The aim of this study is to propose a socio-technical viability framework for MHP systems to support the energy recovery potential and sustainability ambitions of group water-energy schemes in the EU's Atlantic Area. The objectives are to:

1. Understand the extent to which stakeholder knowledge and contextual factors inform the adoption and adoption of MHP systems in the Atlantic Area.

2. Evaluate and validate the viability criteria for MHP systems as defined in the conceptual framework. This includes assessing the provisional framework for relevance, relationships, completeness and redundancies. Mutual dependencies, correlative or hierarchical analysis and weightings are outside the scope of this paper.

3. Determine the opportunities and barriers to the adoption of MHP systems based on stakeholder benefit and risk perceptions.

The findings provide a mechanism to understand the social, environmental, institutional and political factors that affect the decision making in the adoption of MHP.

\section{Frameworks and Themes for Social Readiness for Technology Adoption}

RE systems, such as MHP, are socio-technical systems. Therefore, implementation strategies in both domains are necessary to promote viability and adoption. Socio-technical studies argue that human organisation require an integration of these two systems: the social system which helps form relationships via tasks and goals and the technical system that presents these structured tasks and goals $[43,44]$. Frameworks and models exist in literature to address the user, technology, market and institutional aspects of technological interventions and resource use. For instance, the POEM framework (Figure 1) accounts for fundamental market dynamics which supports innovators, entrepreneurs and product managers to account for market conditions, helping to determine the likelihood of the success of an idea [45]. It covers five themes: the customer, the product, finance, timing and competition. It states that these factors need to be present and understood for a new technological innovation or product to succeed. However, the primary focus of frameworks like POEM is to evaluate the market opportunity. It also does not consider social and physical factors, nor the institutional and cultural context. In addition, it does not provide guidance for evaluating opportunities to promote change or to facilitate a positive social, technological or economic environment within which technological innovation can flourish.

Socio-technical models, such as by Yun and Lee [16], on the other hand, provide a more cohesive approach, as it combines the theory behind the planned behaviour model with socio-technical factors. In this study, a quantitative approach was used to understand sociotechnical factors which users consider the most critical. The resulting model (Figure 2a) proposed the perception of behavioural control, attitudes and subjective norms as important considerations when promoting the adoption of RE systems. It also identifies additional socio-technical perspectives as influential factors.

In the social domain, the models characterised and defined social trust and social support. Social trust is derived based on the perceived benefits or risks, trust in institutions and fairness and equity. Therefore, if institutions linked to RE systems are deemed trustworthy, customers are more likely to expect benefits and avoid risks from adopting 'green' measures. The cost-benefit paradigm also impacts people's judgments, as trust influences 
people's opinions and attitudes in relation to technology adoption practices [46]. Social support, including social community support, on the other hand, influences an individual's belief in an institution. To be part of a community who is supportive and informed about new technology can present an open and fair system which affects social support and trust [47].

\begin{tabular}{|l|}
\hline \multicolumn{1}{|c|}{ 1. Customer } \\
\hline - Clearly identifiable \\
customer \\
- Meaningful \\
problem to solve \\
- Segmentable \\
market \\
- Customer \\
accessibility \\
- Customer loyalty \\
\hline
\end{tabular}

\begin{tabular}{|l|}
\hline \multicolumn{1}{|c|}{ 2. Product } \\
\hline - Tight niche focus \\
- No network effect \\
- Lean method \\
viable \\
- Team-to-market fit \\
- Inherent story \\
(Virality) \\
\hline
\end{tabular}

\begin{tabular}{|l|}
\hline \multicolumn{1}{|c|}{ 3. Finance } \\
\hline -Healthy margins \\
- Demand constraint \\
- Supply constraint \\
- Sunk costs \\
- Cashflow \\
requirement \\
\hline
\end{tabular}

\begin{tabular}{|l|}
\hline \multicolumn{1}{|c|}{ 4. Timing } \\
\hline - Secular trend \\
alignment \\
- Recent innovation \\
filter \\
- Market \\
inefficiency \\
- Recent \\
competition surge \\
-Signs of \\
\hline commoditization \\
\hline
\end{tabular}

\begin{tabular}{|l|}
\hline 5. Competition \\
\hline - Limited \\
competition \\
- Competitor fitness \\
- Your team's \\
fitness \\
- Defensible \\
position \\
- Barriers to entry \\
\hline
\end{tabular}

Figure 1. The POEM framework. After Cabage/Zhang 2013 [45].

In the technical domain, perceived system quality (reliability and usability) and the facilitated technical conditions are defined (Figure 2a). Perceived system quality ensure that people are confident that RE can effectively replace traditional energy systems [16]. It affects attitudes, e.g., the ease of use of a system, which affects user behaviour [48]. Michelsen [49] found that any uncertainty among stakeholders can negatively influence the willingness to purchase a RE system, e.g., a solar hot water installation or biomass boiler. Facilitating technical solutions, includes resources (money and time) and technological factors (flexibility, compatibility, customisation, control and usability). Accessible information, technical support and working examples, e.g., demonstration sites or free trials, can also overcome the lack of experience which exists with consumers [49]. By providing technical information, users have perceived control and increased confidence to adopt the systems [16]. Additionally, included in the technical domain are the uncertainties and perceived risks of negative consequences when adopting an innovative product [50]. For instance, the conceptual model by Paluch and Wünderlich [51] categorised perceived risks as financial, functional, privacy, psychological and temporal (Figure 2b). Stakeholder fears can also arise around sensory risk, i.e., impacting one or multiple senses in a negative manner [52].

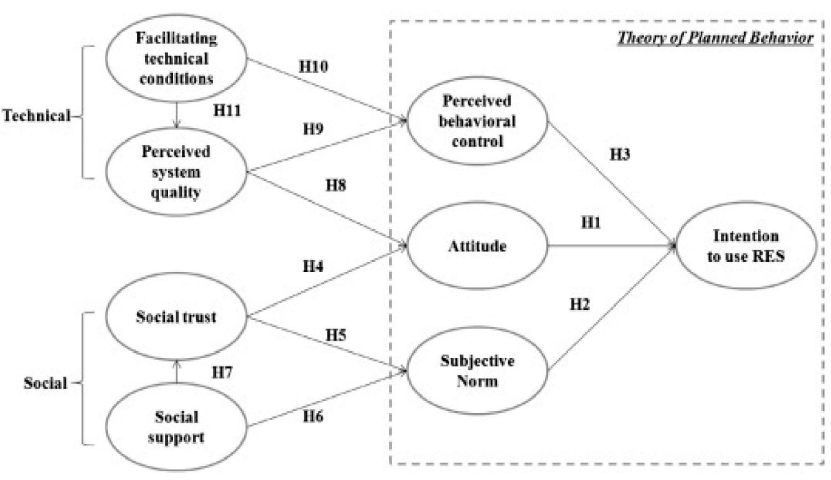

(a)

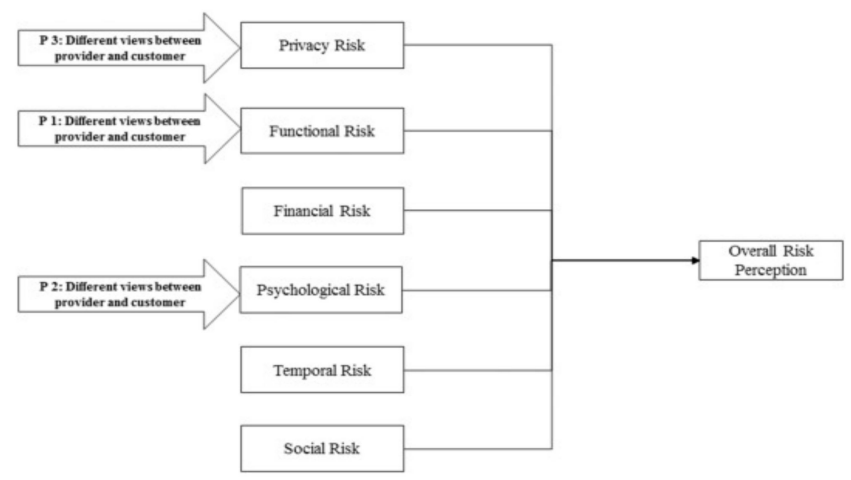

(b)

Figure 2. (a) Theory of planned behaviour with integrated socio-technical factors [16]. (b) A conceptual model presenting the drivers of perceived risk [51]. 
The model in [16] attempted to connect the social and technical domains to determine the intention to use RE systems. The result was an approach which excluded external organisational, institutional or market factors. Social and service innovation emerged as the framework to address this gap. Social innovation presents an intervention, product and process which address the social needs of stakeholders [53]. Service innovation relates to changes in the options and systems of delivery (from concepts to technological solutions) in the water sector, which improves the experiences of stakeholders (i.e., customers) [54]. This can be achieved through assimilation, demarcation and synthesis approaches [55,56].

Assimilation is driven by new technology or products. Demarcation goes beyond innovation in technology and requires a broader approach to innovation [56]. Hence, [57] defined service innovation as the "creation of new value propositions by means of developing existing or creating new practices and/or resources, or by means of integrating practices and resources in new ways". The synthesis perspective suggests that service innovation is the result of several actors, components, contextual aspects and interactions [58].

This perspective also introduces the concept of collaborative communities to the social readiness for technological adoption. Therefore, a socio-technical system for MHP systems could encapsulate a collaborative group of people (prosumers; community) to maximise resources (collaborative). Two mutually dependent outcomes can occur: collaborative services and networks [7]. These produce jointly (peer-to-peer) developed services which are sustainable in nature and create more resilient communities [43]. Collaborative services require network or community collaboration, which leads to innovation and prosumer/community benefits.

The literature review establishes the need for a comprehensive socio-technical approach which incorporates user factors such as social value and support collaborative communities through social and service innovation. These, in turn, will increase the perceptions of system value and quality and reduce perceived risks. Therefore, understanding the individual, institutional and community attitudes, behaviours and decision-making is an essential part of any study on product and service innovation, towards a socio-technical framework to support collaborative services-including for prosumer groups and schemes.

\section{Materials and Methods}

The technical characteristics and performance, environmental and economic merits of MHP systems are out of the scope of this research, as this has been extensively covered in previous work (e.g., [42,59-61]); the less resolved aspects are the social externalities. The impact of the growth of the RE sector is evaluated in the following three dimensions: socioeconomic impacts, including wealth and job creation; environmental impacts, including avoided $\mathrm{CO}_{2}$ emissions; and the reduction of energy dependence.

An inductive approach was adopted by generating a conceptual framework from key literature which was then validated with primary data. This approach is suitable in cases where limited knowledge and understanding is available [62]. The work was done in three stages: (a) a progressive literature review, proposing a conceptual framework; (b) a survey to obtain stakeholder views about awareness, opportunities and barriers, and decision drivers for the adoption of MHP; and (c) an analysis and consolidation of findings to validate the conceptual framework.

Literature review and sampling: A snowballing progressive review approach was utilised, focussed on previously proposed models and frameworks to examine technology diffusion. The review sampled journal papers, predominantly published between 2010-2020, addressed renewable energy schemes, social, institutional and regulatory models and frameworks, as well as technology deployment and adoption of RE. Qualitative thematic analysis was used to shortlist, structure and correlate emerging criteria. This focussed approach produced a 'consensus' underpinned by themes and sub-themes on which further explorations can be based. The findings were then consolidated and visualised as a conceptual framework (Figure 3). 


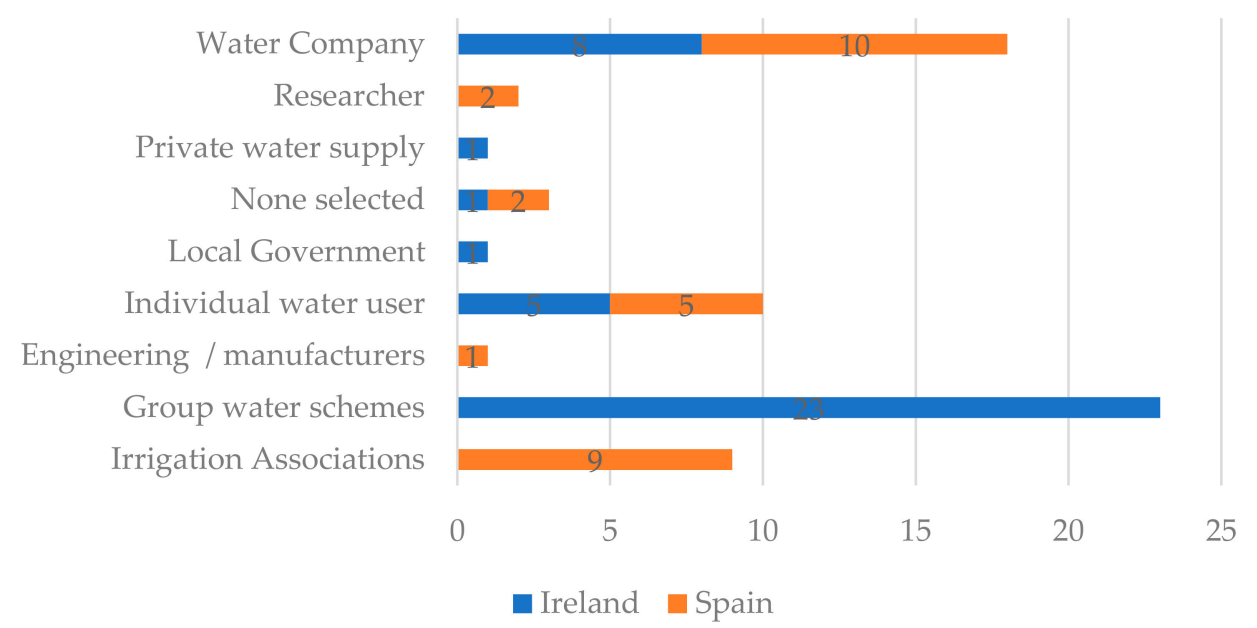

Figure 3. Distribution of the categories of stakeholder respondents in Ireland and Spain.

Conceptual framework: A conceptual framework is a 'plane' of linked concepts which provides an interpretative approach to capturing reality. Its key function is to provide an understanding of the situation rather than provide a theoretical or quantitative explanation of a problem. This allows conceptual frameworks to be flexible, permitting modification with ease, and outputs focussing on understanding the situation [63]. They are extensively used in inductive research studies based on systematic reviews [64] and have been applied to consolidate new knowledge in sustainability transitions (e.g., [65]) and RE studies (e.g., [66]). The MHP conceptual framework can be used to facilitate conceptual quality, i.e., the extent to which concepts are articulated to facilitate theoretical insight [67], because:

1. The lack of literature on the social dimensions and impact of implementing MHP in existing water networks, particularly in Europe, demonstrates the need to better understand the socio-technical context which impacts their successful deployment. These should be studied thematically as well as through the key actors and stakeholders.

2. A systematic approach is required to support the analysis, design and assessment of the ongoing technical developments. A framework can capture social and institutional opportunities and barriers as well as the facilitating technical conditions which are necessary and important in the adoption of MHP as a technological innovation.

Participant sampling: The target stakeholders were water groups (prosumers) who directly or indirectly own or manage utility, irrigation, manufacturing or private water networks used for water and/or energy supply [42]. In addition to policy makers and regulators, this includes academics and engineers that work with water groups to deliver MHP schemes. The stakeholders formed the target group for this EU Atlantic Area-funded project. Thus, the respondents would have engaged with or attended an MHP event where they would have had the opportunity to learn about, ask questions and visit pilot MHP sites. These events took place between 2018-2019 across the EU's Atlantic Area. This opportunistic sampling ensured that respondents were a specific catchment group at an important decision stage of considering the viability of MHP systems for their water networks. This made them and their insights ideal for examining the viability of MHP systems, and to explore the various factors that determined if and how MHP systems were adopted.

Surveys: This method enabled the confirmation and validation of the social, political and cultural MHP adoption criteria of the conceptual framework by representative stakeholders [68]. To avoid bias, questions were not structured to directly corroborate the framework. Instead, the survey consisted of a series of open and closed questions (closed questions provided space for supporting comments) along seven broad themes: stakeholder background; group scheme structure; knowledge and awareness of renewables and MHP systems (contradictions in data are explained by knowledge and awareness 
changes due to engaging with MHP pilot projects or events); water network characteristics and technical affordances; policy and institutional context; perceived risks and benefit of RE and MHP adoption, and, the drivers and barriers to the adoption of MHP systems.

The surveys were piloted at a special session during the Water Efficiency Conference 2018, then revised and deployed at the UK Future Resources Expo 2019 and Carrefour de 1'Eau in France in 2019, using the Turning Technologies TurningPoint App, which allowed polling via voting buttons or online. After further refinement, the survey was then deployed online to irrigation sector groups in Andalucia, Spain and group water schemes in Ireland via their respective associations. Further insight on the GWS in Ireland can be found in [69]. The findings from the two groups form the focus of this paper, enabling comparisons of contexts, water and energy sectors, service and pricing frameworks and RE needs and adoption intent against the themes within the conceptual framework.

In total, 68 individuals linked to water groups responded to the survey from a water irrigation community in Spain (ES) $(n=29)$, and members of an association of group water schemes in Ireland (IE) $(n=39)$. There were 11 female respondents $(\mathrm{ES}=3 ; \mathrm{IE}=8)$, 55 male respondents $(E S=25 ; \mathrm{IE}=30)$ and 2 that elected not to disclose their gender $(\mathrm{ES}=\mathrm{IE}=1)$. The majority of respondents $(n=32)$ were members of a group water scheme either for domestic use in the community or as part of an irrigator network (Figure 3). The next main group consisted of individuals working for water companies $(n=18)$, followed by individual users in domestic $(n=10)$ and irrigation $(n=9)$ networks. The number of responses can be considered a limitation, which was mitigated by the opportunistic nature of the sampling and the focus on the depth, rather than breath, of the data. Further work was undertaken, COVID-19 pandemic permitting, to further validate and improve the scalability of the findings.

Data analysis: The resulting data were consolidated into an Excel spreadsheet for subsequent analysis in IBM SPSS ${ }^{\circledR}$ Statistics software. Due to the specific scope of the study, we focussed on: (a) water networks in the Atlantic Area and (b) validating the themes and criteria that inform the socio-technical viability of MHP systems in water/community groups as found in literature. A descriptive (crosstab) statistical analysis using a fivepoint Likert scale ( 5 being highest) was used to determine first-order and second-order themes. This method is considered good practice in qualitative research [63]. Further in-depth statistical analyses were conducted on the entire dataset, including those from other Atlantic Area regions, but the findings are outside the scope of this paper.

\section{Results}

To satisfy the first objective, the progressive review findings are thematically clustered and visualised as a conceptual framework for evaluating the socio-technical viability MHP systems (Figure 4). The socio-technical framework identified the broad social themes of people and collaborative communities. The sub-themes under 'people' were trust, support and cultural factors, while the sub-themes for collaborative communities were collaborative services and networks. The two technical themes were the technical product, with subthemes of perceived system quality and technical capacity, and product/system facilitation, with sub-themes of customer/consumer, institutions, market and environment.

The findings towards the second objective are presented in the following sections. 


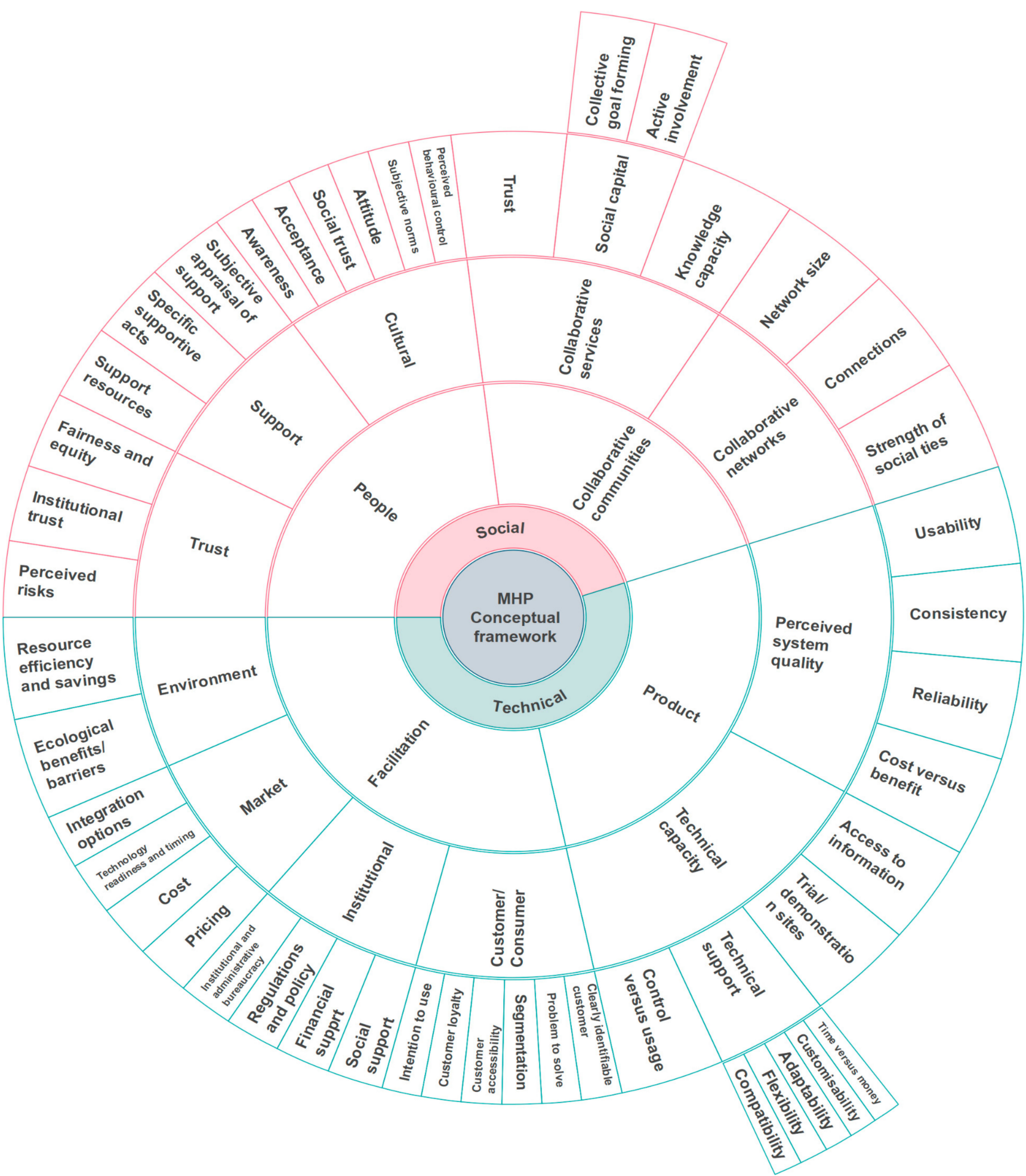

Figure 4. Conceptual framework for MHP implementation.

\subsection{Stakeholder, Awareness and Beneficiaries}

Water company and prosumer group schemes were highlighted as the main water actors in Ireland, whilst public agencies or municipalities were noted as the predominant stakeholders in Spain. The responses on water actors for Spain were more dispersed, with many respondents selecting multiple actors, e.g., irrigator communities, private and public agencies or community groups/collectives. 
The distribution of knowledge of common RE sources among the respondents are shown in Figure 5. The majority $(n=22)$ had medium to expert knowledge of solar energy (photovoltaics (PV) and thermal), 12 of wind energy, 10 of hydro and biomass energy, and 7 of geothermal energy. In total, 30 of the 68 participants consistently responded that they had no direct experiential use of any RE technologies. However, collective or communal systems provided means to indirectly engage with such systems.

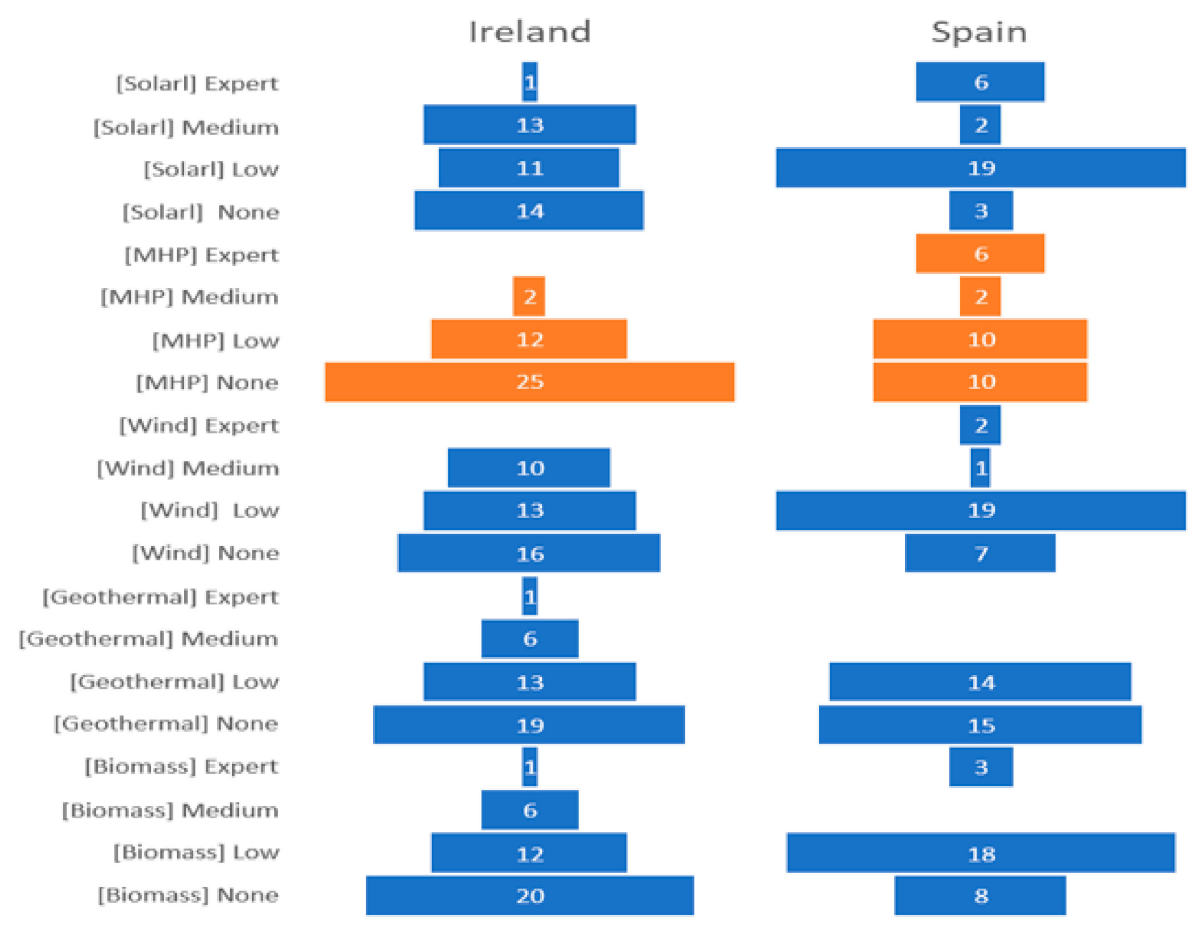

Figure 5. Knowledge of different RE technologies in Ireland and Spain (MHP in orange).

Only IE $=7$ and ES $=8$ respondents stated that they were aware of a specific organisation that promotes environmental innovations and services in their area. A majority of 30 said there were none, while 14 said that they did not know. It was, therefore, not surprising that there were gaps in communication by social or organisational providers for the coordination of local actors to formulate collective goals and action plans, evident local engagement and collaboration, effective management of stakeholders, support of service providers through training or translation of policy from a national to local level. One Spanish respondent stated that information about technological innovations primarily happens by word of mouth: "This technology is very immature and unknown to most of the potential users". Spanish respondents commented on the lack of policy mechanisms to support the adoption of renewables: "Environmentally sustainable energy sources are essential [in addition to auditing of existing energy demand to improve efficiency and build resilience against the impacts of climate change]. ... I think that the installation of at least one RE source should be a planning condition ... as should the provision of alternative energy sources for community water suppliers for whom energy bills account for a huge proportion of operational costs". Another echoed the sentiment by stating that there is a "huge lack of support from county council in relation to all aspects of water quality/supply/conservation/cost savings". One respondent, who managed a private group water scheme for the past 2 years but had worked in the water department for the local authority for 39 years as electrician and Area Supervisor, said that it is up to individuals such as himself to promote positive water and energy action. However, another suggested that: "Training [needs] to be given to those [who are] willing to assume these roles".

The POEM framework highlights the importance of understanding target and nontarget groups for focussed technological innovation and promoting market adoption. To 
establish socio-technical viability requires answers to the questions: Who will benefit? How will they benefit? As a response, participants classified direct beneficiaries as individuals, the community groups and water/energy companies. Indirect beneficiaries were considered as governments at the local, regional, national and transnational (e.g., EU) levels. Responses were measured with a five-point Likert scale, with 1 being no benefit and 5 being significant benefit (Table 1).

Table 1. Potential beneficiaries of $\mathrm{MHP}(\mathrm{IE}=40 ; \mathrm{ES}=28)$.

\begin{tabular}{|c|c|c|c|c|c|c|c|}
\hline Beneficiary & Response & IE & ES & Beneficiary & Response & IE & ES \\
\hline \multirow{6}{*}{ Individuals } & Null & 7 & 8 & \multirow{6}{*}{$\begin{array}{c}\text { Regional } \\
\text { Governments }\end{array}$} & Null & 8 & 9 \\
\hline & 1 No benefit & 0 & 3 & & 1 No benefit & 3 & 6 \\
\hline & 2 & 3 & 5 & & 2 & 3 & 0 \\
\hline & 3 No change & 7 & 4 & & 3 No change & 8 & 7 \\
\hline & 4 & 10 & 4 & & 4 & 6 & 2 \\
\hline & $\begin{array}{l}5 \text { Significant } \\
\text { benefits }\end{array}$ & 13 & 4 & & $\begin{array}{c}5 \text { Significant } \\
\text { benefit }\end{array}$ & 12 & 4 \\
\hline \multirow{6}{*}{ Community } & Null & 4 & 8 & \multirow{6}{*}{$\begin{array}{c}\text { National } \\
\text { Governments }\end{array}$} & Null & 7 & 9 \\
\hline & 1 No benefit & 2 & 2 & & 1 No benefit & 1 & 6 \\
\hline & 2 & 2 & 1 & & 2 & 3 & 1 \\
\hline & 3 No change & 3 & 6 & & 3 No change & 7 & 4 \\
\hline & 4 & 11 & 4 & & 4 & 7 & 6 \\
\hline & $\begin{array}{l}5 \text { Significant } \\
\text { benefits }\end{array}$ & 18 & 7 & & $\begin{array}{c}5 \text { Significant } \\
\text { benefit }\end{array}$ & 15 & 2 \\
\hline \multirow{6}{*}{$\begin{array}{c}\text { Water/Energy } \\
\text { Companies }\end{array}$} & Null & 4 & 9 & \multirow{6}{*}{$\begin{array}{l}\text { Transnational } \\
\text { Governments }\end{array}$} & Null & 8 & 9 \\
\hline & 1 No benefit & 2 & 5 & & 1 No benefit & 2 & 7 \\
\hline & 2 & 3 & 1 & & 2 & 2 & 1 \\
\hline & 3 No change & 6 & 1 & & 3 No change & 8 & 6 \\
\hline & 4 & 5 & 6 & & 4 & 7 & 4 \\
\hline & $\begin{array}{l}5 \text { Significant } \\
\text { benefits }\end{array}$ & 20 & 6 & & $\begin{array}{c}5 \text { Significant } \\
\text { benefit }\end{array}$ & 13 & 1 \\
\hline \multirow{6}{*}{$\begin{array}{c}\text { Local } \\
\text { Governments }\end{array}$} & Null & 7 & 9 & & & & \\
\hline & 1 No benefit & 0 & 5 & & & & \\
\hline & 2 & 2 & 0 & & & & \\
\hline & 3 No change & 5 & 2 & & & & \\
\hline & 4 & 10 & 6 & & & & \\
\hline & $\begin{array}{l}5 \text { Significant } \\
\text { benefits }\end{array}$ & 16 & 6 & & & & \\
\hline
\end{tabular}

For Ireland, respondents indicated that MHP systems will benefit the individual $(n=23)$, group schemes $(n=29)$ and water/energy companies $(n=25)$. The non-target groups were identified as local municipalities $(n=26)$, regional $(n=18)$, national $(n=22)$ and transnational (e.g., EU) $(n=20)$ levels. This suggests that there is the potential for all sectors to benefit from MHP in an Irish context. One respondent highlighted this as follows: "Part of our pipe network is flowing down a great fall and might provide free power ... for some community service". Thus, if the resource and opportunity is already there, respondents were willing for it to be exploited for collective benefit, not necessarily for individual or institutional gain. The Spanish responses were more dispersed, with no emerging consensus. Only 8, 11 and 12 of the 28 respondents considered some benefit for each of the target groups. Twelve respondents indicated that the local government or municipality would benefit, with no significant responses for the other target groups. In general, the remaining responses considered no change, little or no benefit or did not respond to the question. This may be explained by the diverse regional practices of resource abstraction, supply, management and use in Spain, as highlighted by these quotes from Spanish respondents: "It [MHP] mainly benefits [those] who install it, they obtain economic and environmental benefits" and "There is no micro hydroelectric power currently installed in the 
area. However, potential beneficiaries are likely to be at all levels: local, regional, state agencies and service providers".

\subsection{Perceived Impacts and Risks}

In Ireland, water is typically supplied by a singular public water authority. In Irelandespecially in urban areas-there are no direct water charges for domestic users. Charges are currently set at a defined threshold per number of occupants. Excess water charges beyond this threshold have been proposed but has yet to come into force. However, rural areas still face centralised infrastructure challenges and rely on decentralised water supply. These networks are typically private or community-led initiatives that are supported to varying degrees by state funding [69]. This prompted one respondent to state: "Bring back water charges. Then you can have fairer charges, better systems and quality service". Comparatively, water tariffs differ across Spain, as prices are set by municipalities or water agencies.

Hutton [70] stated that most countries have water affordability indices above $4 \%$ for median households and would generally be around $6 \%$ for the first decile of income. However, most countries in the EU have lower affordability thresholds. Evidence suggests that this figure has increased over the past decade in a number of different European countries [71]. The majority in Ireland ( 25 of 38 respondents) stated that they spend less than $5 \%$ of their income on water (and associated services), compared to ES $=11$ of 28 . Affordability was still an issue for IE $=9$ and $\mathrm{ES}=10$, who spent more than $6 \%$ of their income on water. Nevertheless, IE $=11$ and $\mathrm{ES}=17$ would be happy to pay more for water, $\mathrm{IE}=10$ and $\mathrm{ES}=1$ may pay more, whilst $\mathrm{IE}=11$ and $\mathrm{ES}=8$ would not pay more. A small number of participants did not know the answer to this question.

The nature of the water sector, cost of water services and level of involvement in decision making influence the respondents' perceptions of the impact of incorporating RE systems in the sector (Table 2). The majority of respondents would have participated in MHP events during the time of the survey. Therefore, most $(n=26)$ considered that MHP would improve service reliability. Similarly, $26(E S=19 ; \mathrm{IE}=7)$ respondents expected a positive impact, such as social service benefits, e.g., public lighting, electric car charging or offsetting cost for poorer households. However, in Ireland, 18 respondents stated that this will make no change to service reliability, with 10 stating no change in social services. The most notable response was in relation to the environmental impacts of RE, as 45 respondents $(E S=19 ; \mathrm{IE}=26)$ stated a moderate to high positive impact. Second to this was lower water costs by 33 respondents $(E S=22 ; \mathrm{IE}=11)$, although $\mathrm{IE}=12$ stated no change. A total of 29 respondents $(\mathrm{ES}=18 ; \mathrm{IE}=11)$ stated a positive impact on the local economy and 27 respondents ( $E S=18 ; \mathrm{IE}=9$ ) stated a positive impact on energy supply, although in Ireland, IE = 13 stated no change in either of these categories.

The survey also captured six benefit factors for stakeholders to support MHP adoption in their communities. Here, there were no statistically significant differences between the two countries. The collective responses of the 68 respondents (Table 3) showed that between 47 and 61 were either supportive or very supportive of MHP for all factors. A very supportive response was evident if it reduced water bills and energy tariffs for users $(n=51)$ or if it had environmental benefits $(n=61)$, followed by collective community benefits $(n=48)$. Factors such as indirect financial incentives $(n=53)$, improvements in water supply $(n=49)$ and improvements and energy supply were supported $(n=43)$ but were of less importance when considering factors of primary support for the adoption of this RE technology. 
Table 2. Perceived impact of MHP systems in water networks.

\begin{tabular}{|c|c|c|c|c|c|c|c|}
\hline Factor & Response & IE & ES & Factor & Response & IE & ES \\
\hline \multirow{7}{*}{$\begin{array}{l}\text { Service } \\
\text { reliability }\end{array}$} & Positive impact & 10 & 16 & \multirow{7}{*}{$\begin{array}{c}\text { Improved } \\
\text { energy supply }\end{array}$} & Positive impact & 9 & 18 \\
\hline & Moderate impact & 3 & 0 & & Moderate impact & 4 & 0 \\
\hline & Little impact & 4 & 4 & & Little impact & 10 & 5 \\
\hline & No change & 18 & 6 & & No change & 13 & 3 \\
\hline & Negative impact & 1 & 0 & & Negative impact & 0 & 0 \\
\hline & Other & 0 & 0 & & Other & 0 & 1 \\
\hline & null & 4 & 2 & & null & 4 & 1 \\
\hline \multirow{7}{*}{$\begin{array}{c}\text { Lower water } \\
\text { cost }\end{array}$} & Positive impact & 12 & 22 & \multirow{7}{*}{$\begin{array}{l}\text { Improved } \\
\text { environment }\end{array}$} & Positive impact & 14 & 13 \\
\hline & Moderate impact & 5 & 0 & & Moderate impact & 4 & 0 \\
\hline & Little impact & 12 & 3 & & Little impact & 13 & 2 \\
\hline & No change & 8 & 1 & & No change & 6 & 0 \\
\hline & Negative impact & 0 & 0 & & Negative impact & 0 & 0 \\
\hline & Other & 0 & 1 & & Other & 0 & 8 \\
\hline & null & 3 & 1 & & null & 3 & 1 \\
\hline \multirow{7}{*}{$\begin{array}{l}\text { Support social } \\
\text { services }\end{array}$} & Positive impact & 7 & 19 & \multirow{7}{*}{$\begin{array}{l}\text { Support local } \\
\text { economy }\end{array}$} & Positive impact & 11 & 18 \\
\hline & Moderate impact & 5 & 1 & & Moderate impact & 4 & 0 \\
\hline & Little impact & 10 & 3 & & Little impact & 9 & 3 \\
\hline & No change & 13 & 3 & & No change & 13 & 3 \\
\hline & Negative impact & 1 & 0 & & Negative impact & 0 & 0 \\
\hline & Other & 0 & 1 & & Other & 0 & 3 \\
\hline & null & 3 & 1 & & null & 3 & 1 \\
\hline
\end{tabular}

Table 3. Factors influencing the adoption of MHP.

\begin{tabular}{|c|c|c|c|c|c|c|c|}
\hline Factor & Response & IE & ES & Factor & Response & IE & ES \\
\hline \multirow{6}{*}{$\begin{array}{l}\text { Lower water } \\
\text { bills and energy } \\
\text { tariffs for users }\end{array}$} & Null & 2 & 0 & \multirow{6}{*}{$\begin{array}{l}\text { Improvements } \\
\text { in energy supply }\end{array}$} & Null & 2 & 0 \\
\hline & 1 Very unsupportive & 3 & 0 & & 1 Very unsupportive & 2 & 0 \\
\hline & 2 & 0 & 1 & & 2 & 1 & 2 \\
\hline & 3 No change & 7 & 0 & & 3 No change & 7 & 1 \\
\hline & 4 & 2 & 2 & & 4 & 8 & 9 \\
\hline & 5 Very supportive & 26 & 25 & & 5 Very supportive & 20 & 16 \\
\hline \multirow{6}{*}{$\begin{array}{l}\text { Indirect financial } \\
\text { incentives, e.g., } \\
\text { lower } \\
\text { production } \\
\text { expenses; tax in- } \\
\text { centives/rebates }\end{array}$} & Null & 3 & 0 & \multirow{6}{*}{$\begin{array}{l}\text { Environmental } \\
\text { benefits }\end{array}$} & Null & 2 & 0 \\
\hline & 1 Very unsupportive & 2 & 0 & & 1 Very unsupportive & 2 & 0 \\
\hline & 2 & 1 & 1 & & 2 & 0 & 1 \\
\hline & 3 No change & 7 & 1 & & 3 No change & 2 & 0 \\
\hline & 4 & 6 & 6 & & 4 & 4 & 6 \\
\hline & 5 Very supportive & 21 & 20 & & 5 Very supportive & 30 & 21 \\
\hline \multirow{6}{*}{$\begin{array}{l}\text { Improvements } \\
\text { in water supply }\end{array}$} & Null & 3 & 0 & \multirow{6}{*}{$\begin{array}{l}\text { Collective/ } \\
\text { Community } \\
\text { benefits }\end{array}$} & Null & 2 & 0 \\
\hline & 1 Very unsupportive & 2 & 0 & & 1 Very unsupportive & 2 & 0 \\
\hline & 2 & 0 & 1 & & 2 & 0 & 1 \\
\hline & 3 No change & 10 & 5 & & 3 No change & 6 & 1 \\
\hline & 4 & 5 & 3 & & 4 & 2 & 6 \\
\hline & 5 Very supportive & 20 & 19 & & 5 Very supportive & 28 & 20 \\
\hline
\end{tabular}

\subsection{Drivers and Barriers to the Adoption of $M H P$}

A further exploration of the policy drivers and barriers was captured in responses presented in Table 4. For Irish and Spanish respondents, the common and greatest priority drivers were reducing environmental impact and promoting sustainable practices. Medium priorities include generating income, promoting training opportunities and supporting local activities, creating local jobs were similar in medium and low priorities, and increasing land/property value was a low priority. For Spanish respondents, generating income and supporting local activities were medium to high priority, creating jobs was medium priority, training opportunities is low priority. 
Table 4. Policy drivers for MHP in Ireland (IE) and Spain (ES).

\begin{tabular}{cccccccc}
\hline Policy Driver & Response & IE & ES & Policy driver & Response & IE & ES \\
\hline Reducing & Null & 7 & 1 & & Null & 7 & 1 \\
environmental & High priority & 28 & 23 & Creating local & High priority & 8 & 6 \\
impact & Medium priority & 5 & 4 & jobs & Medium priority & 13 & 17 \\
& Low priority & 0 & 0 & & Low priority & 12 & 4 \\
\hline \multirow{2}{*}{ Increasing } & Null & 7 & 1 & Providing & Null & 10 & 2 \\
land/property & High priority & 2 & 6 & training & High priority & 5 & 3 \\
value & Medium priority & 10 & 7 & opportunities & Low priority & 11 & 15 \\
\hline \multirow{2}{*}{ Low priority } & 21 & 14 & & Null & 7 & 1 \\
Generating & Null & 7 & 0 & & High priority & 11 & 11 \\
income & High priority & 10 & 13 & Supporting & Medium priority & 13 & 9 \\
& Medium priority & 15 & 13 & local activities & Low priority & 9 & 7 \\
\hline \multirow{2}{*}{ Promoting } & Low priority & 8 & 2 & & & & \\
sustainable & Null & 9 & 1 & & & \\
practices & Medium priority & 22 & 18 & & & \\
\hline
\end{tabular}

Respondents were then asked to specify the barriers to the adoption of MHP systems in their communities (Figure 6). This Pareto chart shows that addressing the cost, knowledge and policy barriers would resolve up to $80 \%$ of the barriers to MHP implementation. The top barrier was the cost of the technologies and the lack of finance or financial incentives to overcome the cost associated with the purchase, installation and maintenance of systems: "ignorance of the profitability of the different technologies". This ties in with the fifth factor-the cost benefit. The second highest barrier was lack of knowledge-including the lack of available training to address this knowledge deficit. It was, therefore, no surprise that lack of awareness, education and engagement were ranked third. Ranked second were the lack of policy leadership, excessive bureaucracy or political instability/uncertainty/change.

Barriers to the viability and adoption of MPHs in Spain included: "Administrative complexity and problems" and "instability in the regulatory framework". For Ireland, it included " ... the lack of positive encouragement via government policies". Others cited the lack of joined up thinking: "Water remains separate to the energy sector". Policy makers and water companies not understanding social and group scheme support on one hand, whilst community consultation and buy in remains an issue on the other: "Local objections. People not made aware of what was actually happening".

On the theme collaborative services for promoting social support, some respondents queried whether RE initiatives and technological innovation to promote positive environmental cultures should be led by government or private institutions. Trust in such institutions was low, and this could be attributed to poor communication between institutions, community groups and individuals. For instance, IE $=37$ and $\mathrm{ES}=12$ were not aware of any policy for RE generation in association with water production in their local community or area. In Spain, ES = 16 were exposed to policy evidence: 5 cited public media notices as a source, 3 obtained information through local/community groups and 5 have experienced a combination of outlets, including 2 citing direct communication. Conversely, IE $=25$ and ES = 11 did not recollect being consulted on RE initiatives or innovation (Figure 7). Furthermore, 20 and 13 respondents in Ireland and Spain, respectively, stated that no MHP specific policies have been implemented, although IE $=2$ and ES $=9$ respondents stated that some have recently started to be implemented. 


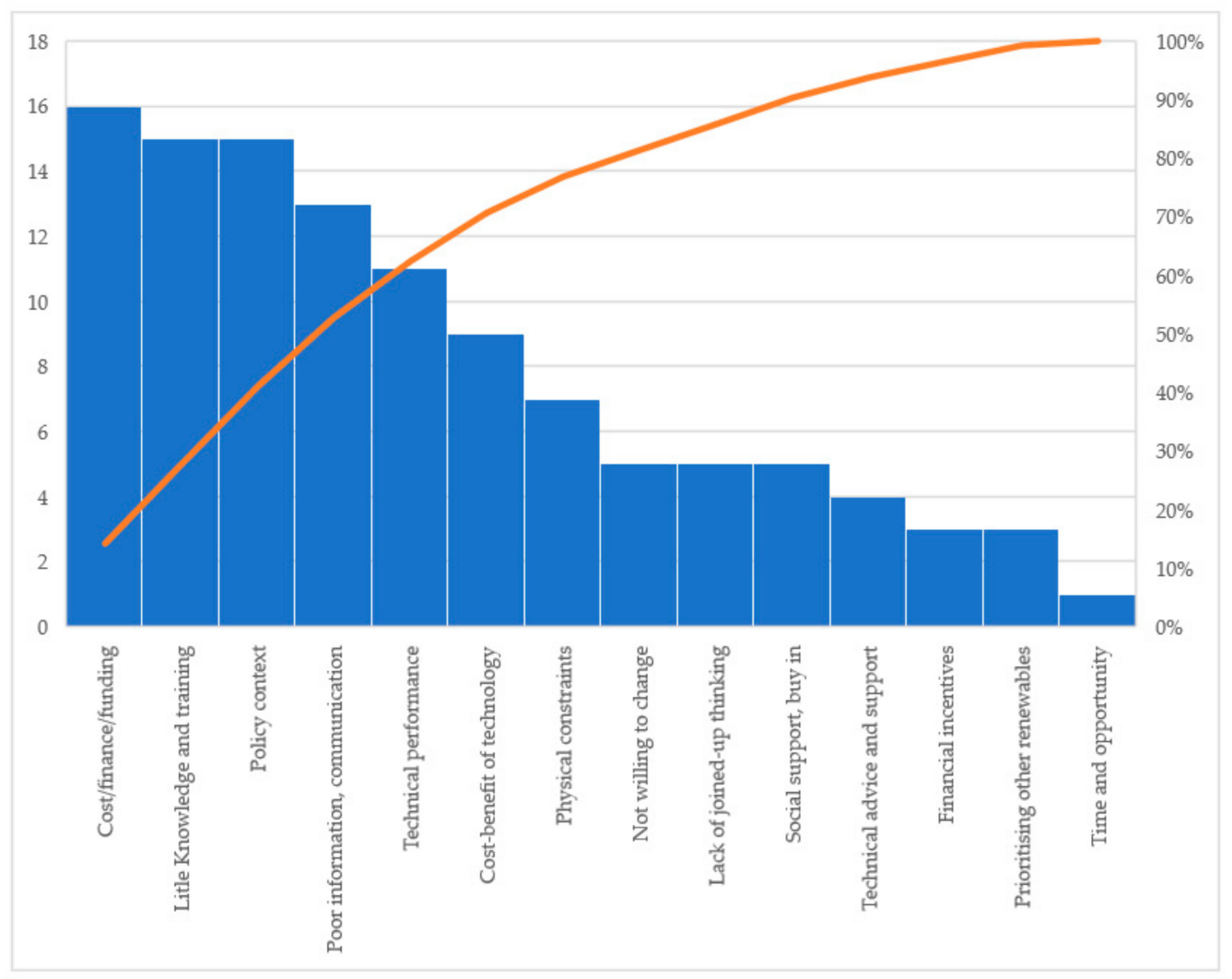

Figure 6. Pareto chart ranking of the policy barriers to implementing MHP.

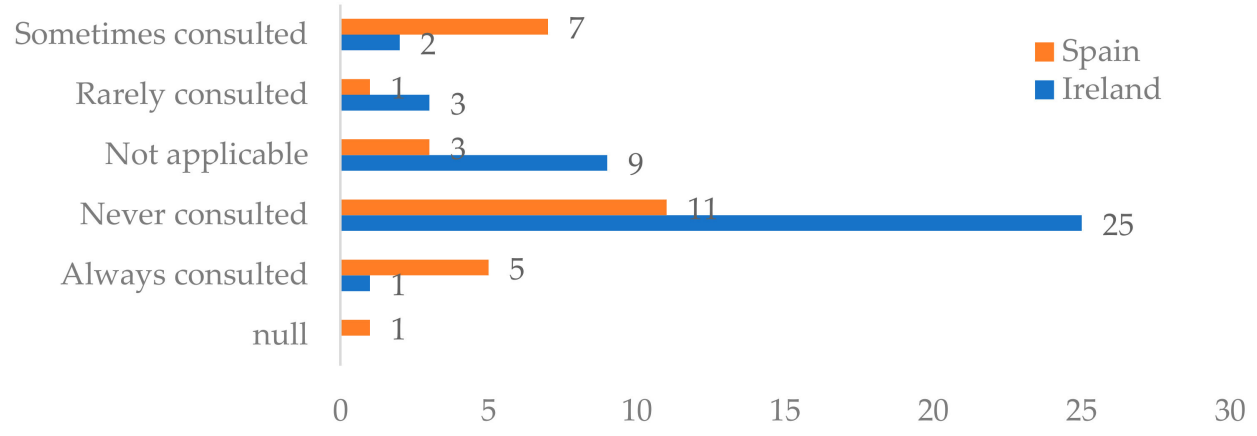

Figure 7. Level of stakeholder consultation on RE, including MHP in Ireland and Spain.

\subsection{Factors to Facilitate MHP Adoption}

In view of these challenges, respondents were asked what was needed to facilitate the adoption of MHP. There was consensus from the majority of respondents from both groups that all factors outlined in Table 5 were essential or highly essential to facilitate the conditions required for increasing the adoption of MHP. These included providing information to increase awareness, administrative support, technical advice and support, financial support and mechanisms and forums to promote collaboration, networking and community-level implementation.

Most facilitation measures concern information and training about MHP technologies and delivering technical and financial support mechanisms to promote its adoption. However, as identified in the assessment of the barriers, the technicality of MHP systems in terms of their perceived performance and benefits was considered important by respondents. Therefore, it was necessary to explore these further. All six factors outlined in Table 6 were considered important or highly important by both groups: usability-easy to install and use, compatibility-with existing system, consistency of supply, reliability-low maintenance and opportunity and local control—ability to trial or see working examples. 
Table 5. Facilitating the adoption of MHP in Ireland (IE) and Spain (ES).

\begin{tabular}{|c|c|c|c|c|c|c|c|}
\hline Facilitators & Responses & IE & ES & Facilitators & Responses & IE & ES \\
\hline \multirow{6}{*}{$\begin{array}{l}\text { Access to } \\
\text { information } \\
\text { about the } \\
\text { technology }\end{array}$} & Null & 3 & 2 & \multirow{6}{*}{$\begin{array}{l}\text { Advisory } \\
\text { Services }\end{array}$} & Null & 3 & 2 \\
\hline & 1 Not essential & 0 & 0 & & 1 Not essential & 0 & 0 \\
\hline & 2 & 3 & 1 & & 2 & 3 & 1 \\
\hline & 3 No change & 0 & 3 & & 3 No change & 2 & 3 \\
\hline & 4 & 4 & 8 & & 4 & 10 & 14 \\
\hline & 5 Highly essential & 30 & 12 & & 5 Highly essential & 22 & 8 \\
\hline \multirow{6}{*}{$\begin{array}{l}\text { Technical } \\
\text { support } \\
\text { services }\end{array}$} & Null & 3 & 2 & \multirow{6}{*}{$\begin{array}{c}\text { Training } \\
\text { opportunities }\end{array}$} & null & 3 & 4 \\
\hline & 1 Not essential & 0 & 0 & & 1 Not essential & 0 & 2 \\
\hline & 2 & 2 & 1 & & 2 & 3 & 0 \\
\hline & 3 No change & 1 & 3 & & 3 No change & 2 & 8 \\
\hline & 4 & 9 & 9 & & 4 & 14 & 9 \\
\hline & 5 Highly essential & 25 & 13 & & 5 Highly essential & 18 & 5 \\
\hline \multirow{6}{*}{$\begin{array}{l}\text { Financial } \\
\text { Support } \\
\text { services }\end{array}$} & Null & 3 & 2 & \multirow{6}{*}{$\begin{array}{l}\text { Network/ } \\
\text { community } \\
\text { support } \\
\text { service }\end{array}$} & null & 2 & 2 \\
\hline & 1 Not essential & 0 & 0 & & 1 Not essential & 0 & 1 \\
\hline & 2 & 2 & 0 & & 2 & 2 & 0 \\
\hline & 3 No change & 2 & 5 & & 3 No change & 3 & 5 \\
\hline & 4 & 9 & 13 & & 4 & 9 & 11 \\
\hline & 5 Highly essential & 24 & 8 & & 5 Highly essential & 24 & 9 \\
\hline \multirow{6}{*}{$\begin{array}{l}\text { Administrative/ } \\
\text { staffing } \\
\text { support }\end{array}$} & Null & 3 & 2 & & & & \\
\hline & 1 Not essential & 0 & 0 & & & & \\
\hline & 2 & 3 & 3 & & & & \\
\hline & 3 No change & 7 & 6 & & & & \\
\hline & 4 & 11 & 11 & & & & \\
\hline & 5 Highly essential & 16 & 6 & & & & \\
\hline
\end{tabular}

Table 6. Technical factors for the viability and adoption of MHP in Ireland (IE) and Spain (ES).

\begin{tabular}{|c|c|c|c|c|c|c|c|}
\hline & & IE & ES & & & IE & ES \\
\hline \multirow{6}{*}{$\begin{array}{l}\text { Usability- } \\
\text { easy } \\
\text { to install and } \\
\text { use }\end{array}$} & Null & 2 & 3 & \multirow{6}{*}{$\begin{array}{l}\text { Reliability- } \\
\text { low } \\
\text { maintenance }\end{array}$} & Null & 3 & 3 \\
\hline & 1 Not important & 1 & 0 & & 1 Not important & 1 & 1 \\
\hline & 2 & 3 & 0 & & 2 & 3 & 0 \\
\hline & 3 No change & 1 & 5 & & 3 No change & 1 & 3 \\
\hline & 4 & 7 & 7 & & 4 & 6 & 12 \\
\hline & $\begin{array}{c}5 \text { Extremely } \\
\text { important }\end{array}$ & 26 & 13 & & $\begin{array}{l}5 \text { Extremely } \\
\text { important }\end{array}$ & 26 & 9 \\
\hline \multirow{6}{*}{$\begin{array}{l}\text { Compatibility } \\
\text {-with your } \\
\text { existing } \\
\text { system }\end{array}$} & Null & 3 & 3 & \multirow{6}{*}{$\begin{array}{l}\text { Local control- } \\
\text { ability to } \\
\text { determine } \\
\text { when it is used } \\
\text { and gain the } \\
\text { benefit }\end{array}$} & Null & 4 & 4 \\
\hline & 1 Not important & 1 & 0 & & 1 Not important & 0 & 1 \\
\hline & 2 & 3 & 0 & & 2 & 3 & 0 \\
\hline & 3 No change & 3 & 4 & & 3 No change & 3 & 7 \\
\hline & 4 & 7 & 5 & & 4 & 12 & 5 \\
\hline & $\begin{array}{l}5 \text { Extremely } \\
\text { important }\end{array}$ & 23 & 16 & & $\begin{array}{l}5 \text { Extremely } \\
\text { important }\end{array}$ & 18 & 11 \\
\hline \multirow{6}{*}{$\begin{array}{l}\text { Consistency of } \\
\text { supply }\end{array}$} & Null & 3 & 3 & \multirow{6}{*}{$\begin{array}{l}\text { Opportunity } \\
\text { to trial or see } \\
\text { working } \\
\text { examples }\end{array}$} & Null & 2 & 3 \\
\hline & 1 Not important & 0 & 0 & & 1 Not important & 0 & 0 \\
\hline & 2 & 3 & 2 & & 2 & 3 & 1 \\
\hline & 3 No change & 2 & 4 & & 3 No change & 0 & 5 \\
\hline & 4 & 3 & 9 & & 4 & 7 & 8 \\
\hline & $\begin{array}{l}5 \text { Extremely } \\
\text { important }\end{array}$ & 29 & 10 & & $\begin{array}{l}5 \text { Extremely } \\
\text { important }\end{array}$ & 28 & 11 \\
\hline
\end{tabular}

\section{Discussion and Consolidated Framework}

The establishment of socio-technical factors which inform the viability and adoption of MHP is especially important in prosumer group schemes as they are impacted by a range of factors (cultural, institutional and technological) within a complex social environment [17]. Therefore, the need to consider an integrated approach is not just limited to technological 
innovations [56]. For this reason, a conceptual framework was developed and evaluated for conceptual quality [68], and then validated using a stakeholder survey. This section discusses the findings to deliver the third objective of the study.

The validation of the framework based on the survey findings explored pre-established themes and sub-themes from literature for RE systems in general, to affirm or disprove their relevance and applicability for MHP. Figure 8 shows the updated framework. Some social sub-themes, such as strength of social ties, collaborations and connections, social trust, subjective norms and perceived behavioural control, were not upheld by the stakeholders in this study. Under the technical category, access to technical information without the institutional and social support networks, clearly identifiable customers, customer and market segmentation, customer loyalty, technology readiness and timing, as well as technology integration options, e.g., with other technologies, were also not affirmed. This is not to say that these social and technical factors are not important; thus, further studies are needed. However, it confirms that some prevalent strategies in technological innovation and market transformation need a rethink of the emphasis and to consider that socio-technical factors could interact in other ways to affect the viability and adoption of MHP and other RE technologies.

In addition to the conceptual framework, the review showed that technology adoption extends beyond technological readiness or market opportunity. Market factors, such as technology readiness, timing, competition, and promotion strategies, e.g., customer targeting and segmentation, were not as paramount in this instance. Unlike frameworks such as POEM [45], the survey findings showed that it is necessary for the customer/prosumer to have a problem to solve, e.g., the need for an alternative energy source, for them to even consider technologies such as MHP systems in the first instance. Cost and finance opportunities were also recurring themes. The initial cost of investment was not considered a barrier if there were policy, regulatory or financial incentives to mitigate. Furthermore, respondents were willing to forgo direct cost benefits for indirect community and social value, or if it maximises the potential and circularity of resources $[5,6]$ or significantly reduces the environmental impact of energy generation and resource use.

This study affirmed most of the themes defined in Yun and Lee's [16] model. However, sub-themes such as strength of social ties, direct collaborations and connections were not considered essential if other collaborative services to promote trust, social capital and knowledge capacity were in place. The validated framework also affirms previous work, e.g., by de Vries and van Vuuren [4], which found that physical context, i.e., geographical location, and institutional and regulatory context can affect the viability and adoption of MHP. These contextual factors can include the potential to connect the MHP generation source to point of demand and use, especially in rural or remote areas where the nature of the water sector could inform centralised or devolved responsibilities for water and energy abstraction, treatment, distribution and supply. It could also inform water and energy pricing and billing. The disparity in how water and energy are charged raised issues of affordability and equity of existing systems, which then led to distrust in gaining any direct benefit from new RE approaches. It is worth noting that the contextual factors are dependent on the policy and regulatory frameworks in different countries and regions. In this study, the contextual factors were different in the two cases, and influenced different perceptions of risk, trust, fairness and equity as well as the perceived individual and collective benefit of MHP adoption and use. Therefore, it was confirmed that MHP adoption is influenced by stakeholders' perception as well as technological push and societal pull factors $[15,16]$.

Social and service innovation were also affirmed. Strategies such as messaging, policy and institutional-led initiatives can be deployed to address awareness gaps and lack of knowledge capacity amongst potential users. A proactive and cost-effective approach for technology providers, water utilities and policy makers to achieve this quickly and effectively is to create target and support collaborative communities, prosumers and networks [43]. Then, collaborative services can be promoted by appraising need and providing 
the necessary network resources, e.g., technical advisory services, or improving technical capacity, e.g., through trial opportunities or demonstration sites. These strategies tie in with the necessary aspects of service innovation and could include structural institutional and regulatory change [54], such as joined-up approach to water and energy services and enhancing delivery of new or added value [57], beyond the supply of resources or cost/billing incentives.

In summary, this work confirms that strategies to address stakeholder perception through communication, social and service innovation, collaborative services and networks, as well as the understanding of contextual aspects, actors and interactions [58], are necessary for the socio-technical viability and adoption of MHP.

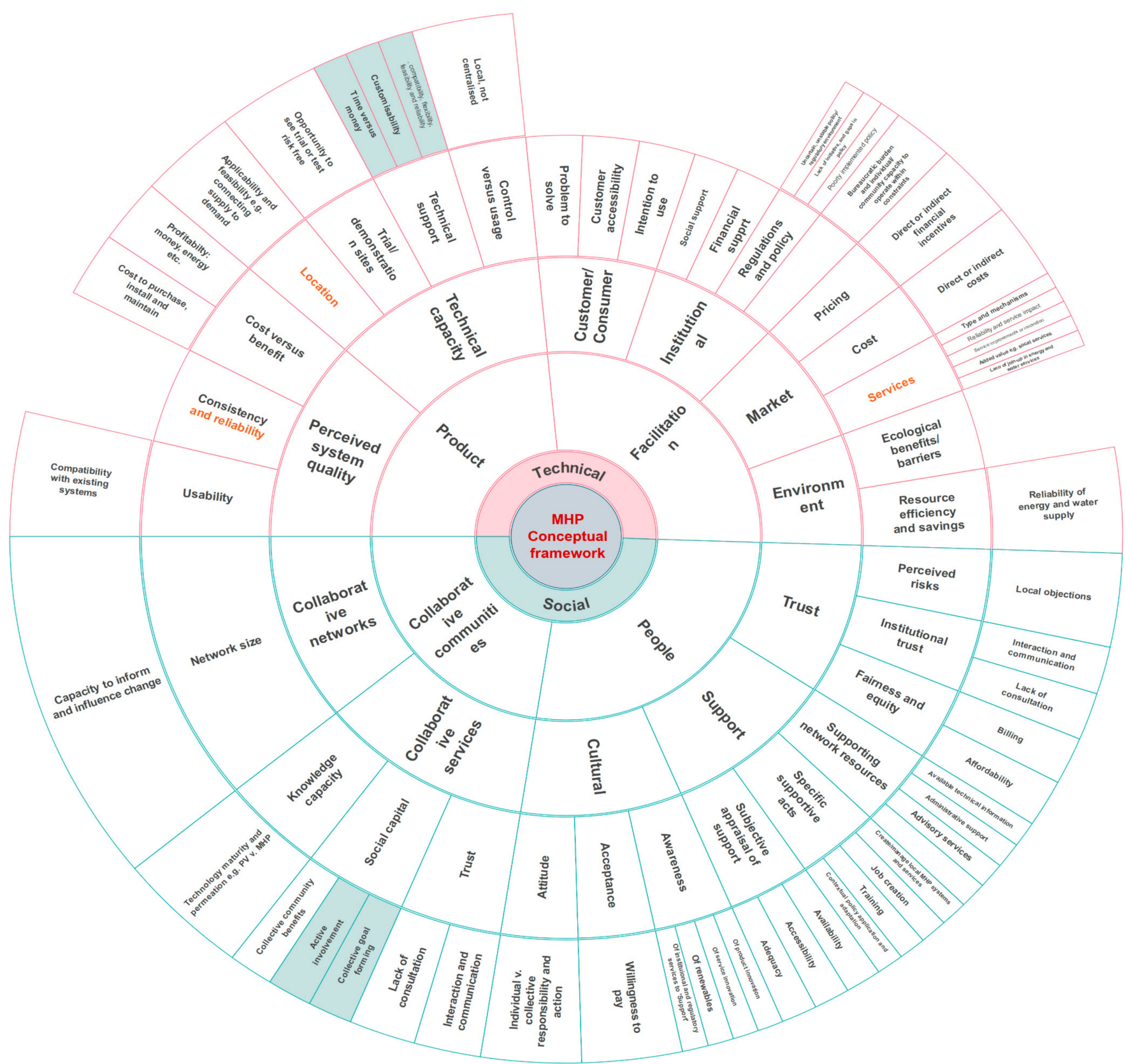

Figure 8. Validated conceptual framework for the viability and adoption of MHP (missing discounted themes, new sub-themes highlighted in orange). 


\section{Conclusions}

This study aimed to investigate the qualitative concepts for evaluating the sociotechnical viability of Micro Hydropower (MHP) in Europe's Atlantic Area. Three objectives were specified and delivered using the inductive research approach, starting with a progressive review of key literature to formulate a conceptual framework. Data from a stakeholder survey in two case study countries in the EU Atlantic Area (Ireland and Spain) were then used to evaluate and validate the framework. The framework can be extended to any community or organisation where improved interactions between end-users/stakeholders can occur through social and service innovation processes.

In satisfying its aim, the findings affirm the interaction between technological push (advancements in product development) and societal pull (market/user demand) factors $[15,16]$ as follows:

- Socio-technical factors influence the adoption of MHP systems especially in community energy schemes. However, these factors are geographically, market- and institutionally dependent.

- The assumption of cost-benefit for individuals is not always paramount if other new or added communal value can be demonstrated.

- Technological awareness and knowledge capacity are necessary for customers and users to embrace MHP and RE systems.

- Service innovation by providers, e.g., to reduce environmental impact, improve service reliability, reduce cost—not just financial—and deliver other social values or goods, e.g., streetlighting job creation, will encourage trust, willingness to pay and general positive response to RE systems such as MHP.

- Social innovation through community-led schemes and targeted services for and with such collaborative networks and groups are an effective way to promote both technical and social capacity, feasibility and adoption of MHP, e.g., through information and advisory services, technical and cost liaison facilities and demonstration sites.

The limitations of this study include the targeted literature approach and limited sample size for the survey. Nevertheless, rigour was demonstrated in the methodological approach and the resulting framework provides a useful template for evaluating the sociotechnical feasibility of MHP based on a more realistic integrated, multi-dimensional criteria, rather than just technology readiness or cost-benefit calculations. The next stages of the work will consist of a social impact analysis and further in-depth interviews to upscale these findings.

Author Contributions: Conceptualisation, K.A., A.M. and P.C.; Data curation, J.G.; Formal analysis, K.A.; Investigation, K.A. and H.M.R.; Methodology, K.A., J.G. and P.C.; Validation, H.M.R.; Visualisation, K.A. and J.G.; Writing—original draft, K.A.; Writing—review and editing, K.A. and J.G. All authors have read and agreed to the published version of the manuscript.

Funding: This study is partially funded by the ERDF Interreg Atlantic Area Programme 2014-2020, through the REDAWN: Reducing the Energy Dependency in Atlantic Area Water Networks project [EAPA_198/2016].

Institutional Review Board Statement: Not applicable.

Informed Consent Statement: Prior to participating in the survey, all participants were informed about the project, the basis for participation including confidentiality and anonymity, and the manner and form in which data will be collected, processed and used.

Data Availability Statement: The data presented in this study are available on request from the corresponding author.

Acknowledgments: The authors acknowledge the following contributors to this study-FERAGUA, FAEN, colleagues from the University of Cordoba, Spain and Dawn Murphy of Action Renewables, Northern Ireland. 
Conflicts of Interest: The authors declare no conflict of interest. The funders had no role in the design of the study; in the collection, analyses or interpretation of data; in the writing of the manuscript, or in the decision to publish the results.

\section{References}

1. EIA. International Energy Outlook 2019 with Projections to 2050; Energy Information Administration: Washington, DC, USA, 2019.

2. Moriarty, P.; Honnery, D. What is the global potential for renewable energy? Renew. Sustain. Energy Rev. 2012, 16, $244-252$. [CrossRef]

3. European Commission. A Policy Framework for Climate and Energy in the Period from 2020 to 2030; Contract No.: Technical Report COM [2014] 15; European Commission: Brussels, Belgium, 2014.

4. de Vries, B.J.M.; van Vuuren, D.P.; Hoogwijk, M.M. Renewable energy sources: Their global potential for the first-half of the 21st century at a global level: An integrated approach. Energy Policy 2007, 35, 2590-2610. [CrossRef]

5. Del Borghi, A.; Moreschi, L.; Gallo, M. Circular economy approach to reduce water-energy-food nexus. Curr. Opin. Environ. Sci. Health 2020, 13, 23-28. [CrossRef]

6. Brandoni, C.; Bošnjaković, B. Energy, food and water nexus in the European Union: Towards a circular economy. Energy 2018, 171, 140-144. [CrossRef]

7. Eurostat. Renewable Energy Statistics; REN: Paris, France, 2020.

8. $\quad$ Eurostat. Wind and Water Provide Most Renewable Electricity; European Commission: Brussels, Belgium, 2020.

9. REN21. Renewables Global Status Report; REN: Paris, France, 2019.

10. Elliott, D. Renewables; IOP Publishing: Bristol, UK, 2013. [CrossRef]

11. Bracken, L.J.; Bulkeley, H.A.; Maynard, C.M. Micro-hydro power in the UK: The role of communities in an emerging energy resource. Energy Policy 2014, 68, 92-101. [CrossRef]

12. Jung, J.; Jung, S.; Lee, J.; Lee, M.; Kim, H.S. Analysis of Small Hydropower Generation Potential: (2) Future Prospect of the Potential under Climate Change. Energies 2021, 14, 3001. [CrossRef]

13. Hernandez, J.C.; Peñas, C.J.; Tiu, A.R.; Charlle, S. A Multi-period Optimization Model for the Design of an Off-Grid Micro Hydro Power Plant with Profitability and Degradation Considerations. Process. Integr. Optim. Sustain. 2021, 5, 193-205. [CrossRef]

14. Chacón, M.C.; Díaz, J.A.R.; Morillo, J.G.; McNabola, A. Evaluation of the design and performance of a micro hydropower plant in a pressurised irrigation network: Real world application at farm-level in Southern Spain. Renew. Energy 2021, 169, 1106-1120. [CrossRef]

15. Smith, A.; Stirling, A.; Berkhout, F. The governance of sustainable socio-technical transitions. Res. Policy 2005, 34, 1491-1510. [CrossRef]

16. Yun, S.; Lee, J. Advancing societal readiness toward renewable energy system adoption with a socio-technical perspective. Technol. Forecast. Soc. Chang. 2015, 95, 170-181. [CrossRef]

17. Kling, R. Learning about Information Technologies and Social Change: The Contribution of Social Informatics. Inf. Soc. 2000, 16, 217-232. [CrossRef]

18. Moriarty, P.; Honnery, D. Rise and Fall of the Carbon Civilisation: Resolving Global Environmental and Resource Problems; Springer Science \& Business Media: Berlin, Germany, 2010.

19. Spreng, D. Distribution of energy consumption and the 2000W/capita target. Energy Policy 2005, 33, 1905-1911. [CrossRef]

20. Overland, I. EU climate and energy policy: New challenges for old energy suppliers. In New Political Economy of Energy in Europe: Power to Project, Power to Adapt; Godzimirski, J.M., Ed.; Springer International Publishing: Cham, Switzerland, 2019 ; pp. 73-102.

21. Genus, A.; Iskandarova, M. Transforming the energy system? Technology and organisational legitimacy and the institutionalisation of community renewable energy. Renew. Sustain. Energy Rev. 2020, 125, 109795. [CrossRef]

22. Heldeweg, M.A.; Séverine, S. Renewable energy communities as 'socio-legal institutions': A normative frame for energy decentralization? Renew. Sustain. Energy Rev. 2020, 119, 109518. [CrossRef]

23. Lowitzsch, J.; Hoicka, C.E.; van Tulder, F.J. Renewable energy communities under the 2019 European Clean Energy PackageGovernance model for the energy clusters of the future? Renew. Sustain. Energy Rev. 2020, 122, 109489. [CrossRef]

24. Inês, C.; Guilherme, P.L.; Esther, M.G.; Swantje, G.; Stephen, H.; Lars, H. Regulatory challenges and opportunities for collective renewable energy prosumers in the EU. Energy Policy 2020, 138, 111212. [CrossRef]

25. Heffron, R.J.; Talus, K. The evolution of energy law and energy jurisprudence: Insights for energy analysts and researchers. Energy Res. Soc. Sci. 2016, 19, 1-10. [CrossRef]

26. Ramachandra, T.V. Renewable energy transition: Perspective and challenges. In Energy India 2020-A Shape of Things to Come in Indian Energy Sector [Internet]; Saket Projects Ltd.: Ahmedabad, India, 2011; pp. 175-183.

27. Wu, X.D.; Guo, J.L.; Meng, J.; Chen, G.Q. Energy use by globalized economy: Total-consumption-based perspective via multiregion input-output accounting. Sci. Total Environ. 2019, 662, 65-76. [CrossRef]

28. Hicks, J.; Ison, N. An exploration of the boundaries of 'community' in community renewable energy projects: Navigating between motivations and context. Energy Policy 2018, 113, 523-534. [CrossRef]

29. Carravetta, A.; Fecarotta, O.; Ramos, H.M.; Mello, M.; Rodriguez-Diaz, J.A.; Morillo, J.G.; Adeyeye, K.; Coughlan, P.; Gallagher, J.; McNabola, A. Reducing the Energy Dependency of Water Networks in Irrigation, Public Drinking Water, and Process Industry: REDAWN Project. Proceedings 2018, 2, 681. [CrossRef] 
30. McNabola, A.; Coughlan, P.; Williams, A.P. Energy recovery in the water industry: An assessment of the potential of microhydropower. Water Environ. J. 2014, 28, 294-304. [CrossRef]

31. Ramos, H.; Covas, D.; Araujo, L.; Mello, M. Available energy assessment in water supply systems. In Proceedings of the XXXI IAHR Congress Conference, Seoul, Korea, 11-16 September 2005.

32. Chacón, M.C.; Rodríguez-Díaz, J.A.; Morillo, J.G.; Gallagher, J.; Coughlan, P.; McNabola, A. Potential Energy Recovery Using Micro-Hydropower Technology in Irrigation Networks: Real-World Case Studies in the South of Spain. Proceedings 2018, 2, 679. [CrossRef]

33. Gallagher, J.; Harris, I.M.; Packwood, A.J.; McNabola, A.; Williams, A.P. A strategic assessment of micro-hydropower in the UK and Irish water industry: Identifying technical and economic constraints. Renew. Energy 2015, 81, 808-815. [CrossRef]

34. Gallagher, J.; Styles, D.; McNabola, A.; Williams, A.P. Life cycle environmental balance and greenhouse gas mitigation potential of micro-hydropower energy recovery in the water industry. J. Clean. Prod. 2015, 99, 152-159. [CrossRef]

35. Bódis, K.; Monforti, F.; Szabó, S. Could Europe have more mini hydro sites? A suitability analysis based on continentally harmonized geographical and hydrological data. Renew. Sustain. Energy Rev. 2014, 37, 794-808. [CrossRef]

36. Gallagher, J.; Coughlan, P.; Williams, A.P.; McNabola, A. Innovating for low-carbon energy through hydropower: Enabling a conservation charity's transition to a low-carbon community. Creat. Innov. Manag. 2018, 27, 375-386. [CrossRef]

37. Heiskanen, E.; Jalas, M.; Rinkinen, J.; Tainio, P. The local community as a "low-carbon lab": Promises and perils. Environ. Innov. Soc. Transit. 2015, 14, 149-164. [CrossRef]

38. Moloney, S.; Horne, R.E.; Fien, J. Transitioning to low carbon communities-From behaviour change to systemic change: Lessons from Australia. Energy Policy 2010, 38, 7614-7623. [CrossRef]

39. Vernay, A.-L.; Sebi, C. Energy communities and their ecosystems: A comparison of France and the Netherlands. Technol. Forecast. Soc. Chang. 2020, 158, 120123. [CrossRef]

40. Ali, A.; Li, W.; Hussain, R.; He, X.; Williams, B.W.; Memon, A.H. Overview of Current Microgrid Policies, Incentives and Barriers in the European Union, United States and China. Sustainability 2017, 9, 1146. [CrossRef]

41. Antioco, M.; Kleijnen, M. Consumer adoption of technological innovations: Effects of psychological and functional barriers in a lack of content versus a presence of content situation. Eur. J. Mark. 2010, 44, 1700-1724. [CrossRef]

42. Chacón, M.C.; Rodríguez Díaz, J.A.; García Morillo, J.; McNabola, A. Estimating regional potential for micro-hydropower energy recovery in irrigation networks on a large geographical scale. Renew. Energy 2020, 155, 396-406. [CrossRef]

43. Baek, J.S.; Kim, S.; Pahk, Y.; Manzini, E. A sociotechnical framework for the design of collaborative services. Des. Stud. 2018, 55, 54-78. [CrossRef]

44. Trist, E.L. The Evolution of Socio-Technical Systems: A Conceptual Framework and an Action Research Program; Ontario Ministry of Labour, Ontario Quality of Working Life Centre: Toronto, ON, USA, 1981.

45. Cabage, N. A Framework for Evaluating Market Opportunity. 2013. Available online: https://www.mindtheproduct.com/2013 /05/poem-framework/ (accessed on 9 September 2020).

46. Midden, C.J.H.; Huijts, N.M.A. The role of trust in the affective evaluation of novel risks: The case of $\mathrm{CO}_{2}$ storage. Risk Anal. 2009, 29, 743-751. [CrossRef]

47. Huijts, N.M.A.; Molin, E.J.E.; Steg, L. Psychological factors influencing sustainable energy technology acceptance: A review-based comprehensive framework. Renew. Sustain. Energy Rev. 2012, 16, 525-531. [CrossRef]

48. Vance, A.; Elie-Dit-Cosaque, C.; Straub, D. Examining Trust in Information Technology Artifacts: The Effects of System Quality and Culture. J. Manag. Inf. Syst. 2008, 24, 73-100. [CrossRef]

49. Claudy, M.C.; Michelsen, C.; O'Driscoll, A. The diffusion of microgeneration technologies-Assessing the influence of perceived product characteristics on homeowners' willingness to pay. Energy Policy 2011, 39, 1459-1469. [CrossRef]

50. Featherman, M.S.; Valacich, J.S.; Wells, J.D. Is that authentic or artificial? Understanding consumer perceptions of risk in e-service encounters. Inf. Syst. J. 2006, 16, 107-134. [CrossRef]

51. Paluch, S.; Wünderlich, N.V. Contrasting risk perceptions of technology-based service innovations in inter-organizational settings. J. Bus. Res. 2016, 69, 2424-2431. [CrossRef]

52. Lovelock, C.H. Services Marketing: People, Technology, Strategy; Prentice Hall: Hoboken, NJ, USA, 2001.

53. European Commission. Guide to Social Innovation; European Commission: Brussels, Belgium, 2013.

54. Ward, S.; Brown, S.; Burton, A.; Adeyeye, K.; Mannion, N.; Tahir, S.; Gordon, C.; Chen, G. Water Sector Service Innovation: What, Where and Who? Br. J. Environ. Clim. Chang. 2016, 6, 216-236. [CrossRef]

55. Coombs, R.; Miles, I. Innovation, measurement and services: The new problematique. In Innovation Systems in the Service Economy: Measurement and Case Study Analysis; Metcalfe, J.S., Miles, I., Eds.; Springer: Boston, MA, USA, 2000; pp. 85-103.

56. Witell, L.; Snyder, H.; Gustafsson, A.; Fombelle, P.; Kristensson, P. Defining service innovation: A review and synthesis. J. Bus. Res. 2016, 69, 2863-2872. [CrossRef]

57. Skålén, P.; Gummerus, J.; von Koskull, C.; Magnusson, P.R. Exploring value propositions and service innovation: A servicedominant logic study. J. Acad. Mark. Sci. 2015, 43, 137-158. [CrossRef]

58. Toivonen, M.; Tuominen, T. Emergence of innovations in services. Serv. Ind. J. 2009, 29, 887-902. [CrossRef]

59. Berrada, A.; Bouhssine, Z.; Arechkik, A. Optimisation and economic modeling of micro hydropower plant integrated in water distribution system. J. Clean. Prod. 2019, 232, 877-887. [CrossRef] 
60. Mdee, O.J.; Kimambo, C.Z.M.; Nielsen, T.K.; Kihedu, J. A technical evaluation of performance characteristics for pump as turbine application. In Renewable Energy and Sustainable Buildings: Selected Papers from the World Renewable Energy Congress WREC 2018; Sayigh, A., Ed.; Springer International Publishing: Cham, Switzerland, 2020; pp. 303-311.

61. García, I.F.; Ferras, D.; McNabola, A. Potential of Energy Recovery and Water Saving Using Micro-Hydropower in Rural Water Distribution Networks. J. Water Resour. Plan. Manag. 2019, 145, 05019001. [CrossRef]

62. Eisenhardt, K.M.; Graebner, M.E.; Sonenshein, S. Grand Challenges and Inductive Methods: Rigor without Rigor Mortis. Acad. Manag. J. 2016, 59, 1113-1123. [CrossRef]

63. Jabareen, Y. Building a Conceptual Framework: Philosophy, Definitions, and Procedure. Int. J. Qual. Methods 2009, 8, 49-62. [CrossRef]

64. Hong, Q.N.; Pluye, P. A Conceptual Framework for Critical Appraisal in Systematic Mixed Studies Reviews. J. Mix. Methods Res. 2019, 13, 446-460. [CrossRef]

65. Edmondson, D.L.; Kern, F.; Rogge, K.S. The co-evolution of policy mixes and socio-technical systems: Towards a conceptual framework of policy mix feedback in sustainability transitions. Res. Policy 2019, 48, 103555. [CrossRef]

66. Kealy, T. A closed-loop renewable energy evaluation framework. J. Clean. Prod. 2020, 251, 119663. [CrossRef]

67. Toye, F.; Seers, K.; Allcock, N.; Briggs, M.; Carr, E.; Andrews, J.; Barker, K. ‘Trying to pin down jelly'—Exploring intuitive processes in quality assessment for meta-ethnography. BMC Med. Res. Methodol 2013, 13, 46. [CrossRef] [PubMed]

68. Gehman, J.; Glaser, V.L.; Eisenhardt, K.M.; Gioia, D.; Langley, A.; Corley, K.G. Finding Theory-Method Fit: A Comparison of Three Qualitative Approaches to Theory Building. J. Manag. Inq. 2018, 27, 284-300. [CrossRef]

69. Devereux, C.; Coscia, J.; Adeyeye, K.; Gallagher, J. Energy Security to Safeguard Community Water Services in Rural Ireland: Opportunities and Challenges for Solar Photovoltaics. Sustain. Energy Technol. Assess. 2021, 47, 101377.

70. Hutton, G. Monitoring "Affordability" of Water and Sanitation Services after 2015: Review of Global Indicator Options; A paper submitted to the UN Office of the High Commissioner for Human Rights. 2012. Available online: https:/ /www.ircwash.org/ resources/monitoring-\%E2\%80\%9Caffordability\%E2\%80\%9D-water-and-sanitation-services-after-2015-review-global (accessed on 9 September 2020).

71. APE. Water Affordability - Public Operators Views and Approaches on Tackling Water Poverty; Aqua Publica Europea [European Association of Public Water Operators]: Brussels, Belgium, 2016. 